\title{
Mapas conceptuales: su uso para verificar el aprendizaje significativo en estudiantes de primaria
}

Concept mapping: its use to verify learning meaningful in elementary students

\section{Volumen 21, Número 1 \\ Enero - Abril \\ pp. 1-31}

\section{José Luis Olivo-Franco}

\section{Citar este documento según modelo APA}

Olivo-Franco, José Luis. (2021). Mapas conceptuales: su uso para verificar el aprendizaje significativo en estudiantes de primaria. Revista Actualidades Investigativas en Educación, 21(1), 1-31. Doi. 10.15517/aie.v21i1.42380 


\section{Mapas conceptuales: su uso para verificar el aprendizaje significativo en estudiantes de primaria}

Concept mapping: its use to verify learning meaningful in elementary students

\section{José Luis Olivo-Franco ${ }^{1}$}

Resumen: Los mapas conceptuales pueden consolidarse como herramientas que, utilizadas intencionalmente, permiten evidenciar los progresos en el aprendizaje de conceptos. Esta investigación, puesta en marcha en el primer semestre de 2017, asumió el estudio de caso como diseño metodológico desde una investigación mixta y, por tanto, utilizó técnicas e instrumentos cualitativos y cuantitativos. Asimismo, se describió la efectividad de los mapas conceptuales para verificar el entendimiento conceptual en una muestra de estudiantes ( $n=13)$ de quinto grado de la Institución Educativa Juan Domínguez Romero de Caracolí-Colombia, con respecto al concepto célula. Los mapas conceptuales del estudiantado fueron instrumentos de obtención de información para verificar el entendimiento conceptual a través de un diseño de medidas repetitivas. Asimismo, a través de entrevistas en profundidad, estos mapas, fueron analizados cualitativamente mediante categorías inductivas y deductivas. El estudio verificó un progreso en el entendimiento conceptual del estudiantado. Se identificaron diferentes niveles de diferenciación conceptual y la persistencia de errores conceptuales que se sugiere, deben superarse mediante instrucción. Se concluye que los mapas conceptuales enmarcados desde la teoría ausbeliana del aprendizaje significativo deben implementarse como herramientas para explicitar ideas previas, errores conceptuales y verificar si un concepto es o no aprendido por el grupo de estudiantes. Prospectivamente, se recomienda explorar sobre la incidencia del uso de los mapas no solo en los procesos cognitivos, sino motivacionales y metacognitivos del estudiantado. Finalmente, dado el potencial pedagógico de los mapas se sugiere sean utilizados intencionalmente por el profesorado para dinamizar su práctica pedagógica y favorecer aprendizajes significativos.

Palabras clave: enseñanza de las ciencias, aprendizaje, conceptualización, comprensión, mapas conceptuales.

Abstract: Concept maps can be consolidated as tools that, used intentionally, allow evidence of progress in learning concepts. This research, launched in the first semester of 2017, assumed the case study as a methodological design from a mixed investigation and, therefore, used qualitative and quantitative techniques and instruments. Likewise, the effectiveness of concept maps to verify conceptual understanding in a sample of fifth-grade students $(n=13)$ from the Juan Domínguez Romero Educational Institution in Caracolí-Colombia, with respect to the cell concept, was described. The student concept maps were instruments for obtaining information to verify conceptual understanding through a repetitive measures design. Likewise, through in-depth interviews, these maps were qualitatively analyzed using inductive and deductive categories. The study verified a progress in the conceptual understanding of the students. Different levels of conceptual differentiation were identified and the persistence of conceptual errors that is suggested must be overcome through instruction. It is concluded that the conceptual maps framed from the Ausbelian theory of meaningful learning should be implemented as tools to make explicit previous ideas, conceptual errors and verify whether or not a concept is learned by the group of students. Prospectively, it is recommended to explore the incidence of the use of maps not only in the cognitive processes, but also in the motivational and metacognitive processes of the student body. Finally, given the pedagogical potential of the maps, it is suggested that they be used intentionally by teachers to stimulate their pedagogical practice and promote meaningful learning.

Keywords: basic science education, conceptualization, comprehension, conceptual maps.

\footnotetext{
1 Doctorando Universidad Pedagógica Experimental Libertador, Venezuela. Orcid https://orcid.org/0000-0002-7781-1261
}

Dirección electrónica: joseolivofranci@hotmail.com

Artículo recibido: 16 de junio, 2020

Enviado a corrección: 9 de setiembre, 2020

Aprobado: 9 de noviembre, 2020 


\section{Introducción}

Las investigaciones en enseñanza de las ciencias han sugerido que las dificultades en el aprendizaje de conceptos científicos pueden superarse si, además de identificar las ideas previas que el estudiantado posee sobre un concepto en particular, se verifica el progreso o no, en el entendimiento que logra después de la mediación docente para tal fin. Asimismo, que estas propuestas en el campo de la didáctica de las ciencias hagan posible a través de construir nuevas estrategias que aporten a la enseñanza significativa de estos conceptos básicos (Aguilera-Morales y Perales-Palacios, 2016; Athitaya, Wiphada, y Lester, 2019; González-Jara, Cueto y Serna, 2015; Pineda y Afanador, 2015).

Es aquí donde los mapas conceptuales utilizados intencionalmente por docentes pueden evidenciar, como señalan Sellman, Liefländer y Bogner (2015), ideas que ya han construido sus estudiantes, también los progresos en el entendimiento conceptual y, por consiguiente, en el aprendizaje significativo de un concepto (Gardner, Lohr, Bartos y Reid, 2019; Kemer, 2020; Ceylan, y Atabek, 2018), o utilizarse incluso como estrategias de adquisición de conocimiento (Olivo, 2017).

Esta investigación da cuenta de cómo los mapas conceptuales evidencian las ideas previas y el incremento del entendimiento conceptual que lograron trece estudiantes de quinto grado $\mathrm{C}$ de la Institución Educativa Juan Domínguez Romero de Caracolí, Malambo- Colombia (IETAC), sobre el concepto célula, después de la mediación docente de Ciencias Naturales a través de estrategias de enseñanza socio-constructivistas.

Respecto a la enseñanza de conceptos científicos, Glagiardi (1986) señala que todos los conceptos en ciencias requieren de un aprendizaje previo, todos son difíciles, pero todos son necesarios. Así, es posible referenciar numerosas investigaciones encaminadas a identificar los conceptos que se le dificultan a la población estudiantil, así como sus ideas previas sobre dichos conceptos (Campanero y Otero, 2000; Gökçe 2018; Gok Colak y Tuğgluk, 2017; Sánchez-Castaño, Castaño-Mejía y Tamayo-Alzate, 2015). Es comprensible, pues, según lo afirman Pineda y Afanador (2015), "la mayoría de los contenidos en ciencias son secuenciales y para su adecuado aprendizaje es necesario contar con unos conceptos previos bien estructurados" (p.42). Particularmente, entre los conceptos más difíciles de entender, los autores citados anteriormente destacan la célula, la célula como contenedora de material hereditario, la mitosis y la meiosis

Por consiguiente, esta investigación pretendió responder las preguntas: 
1. ¿Cómo pueden los mapas conceptuales dar cuenta de las ideas previas de estudiantes de básica primaria de la IETAC?

2. ¿En qué medida los mapas conceptuales pueden ser herramientas que permitan describir el progreso en el entendimiento conceptual logrado por el grupo de estudiantes de quinto grado de primaria sobre el concepto célula? Y finalmente,

3. ¿puede establecerse relación entre el progreso en el entendimiento conceptual logrado por el estudiantado y el número de relaciones conceptuales que establecen?

En coherencia con los interrogantes orientadores de la investigación, se plantearon los siguientes objetivos:

1. Determinar la efectividad de los mapas conceptuales para verificar el nivel de entendimiento conceptual sobre el concepto célula logrado por el estudiantado.

2. Describir, a partir de los mapas conceptuales, las ideas previas y el entendimiento conceptual logrado por el grupo de estudiantes de quinto grado de la IETAC relacionados con el concepto célula.

3. Determinar si existe relación entre el entendimiento conceptual logrado por el estudiantado y las relaciones conceptuales que establecen en sus mapas.

4. Reflexionar sobre las posibles recomendaciones que surjan a partir de los hallazgos de la investigación al profesorado de Ciencias Naturales del municipio de Malambo, orientadas a mejorar su quehacer pedagógico, formación didáctica y la enseñanza de conceptos científicos.

\section{Referente teórico}

Desde la perspectiva teórica del aprendizaje significativo Ausubel, Novak y Hanesian (1983), proponen los mapas conceptuales como herramientas para ayudar al aprendizaje de teorías científicas como recurso para la enseñanza y para la comunicación del conocimiento científico (Jaimes y García, 2013). Para Rivadulla-López, García-Barros y Martínez-Losada (2016), "son diagramas o representaciones gráficas que indican relaciones entre conceptos, o entre palabras que usamos para representar conceptos" (p. 1248).

Igualmente, Zvacek, Restivo y Chouzal (2013) definen los mapas conceptuales así: "son representaciones visuales de cómo organizamos el conocimiento para nosotros y cómo unimos las ideas en una red de nodos y enlaces" (p. 6). En el caso de Arellano y Santoyo 
(2009), los conciben como una imagen visual que permite extraer información, anotar y memorizar detalles con facilidad.

De esta manera, los diversos autores convergen en señalar que, a través de los mapas conceptuales, se pretende representar relaciones significativas entre conceptos en forma de preposiciones o unidades semánticas y que estos conceptos son fáciles de aprender (López, Shavelson, Nandagopal, Szu y Penn, 2014; Tokcan, 2017; Wei y Yue, 2017). Por ejemplo, para Buitrago y Chiappe (2019), el mapeo conceptual hace visible el aprendizaje en la medida que el estudiantado pueda hacer explícito un dominio conceptual, es decir, el entendimiento de un concepto y para Nawani, Von Kotzebue, Rixius, Graml, y Neuhaus (2018), permiten dar cuenta de la estructura cognitiva del grupo de estudiantes sobre un tema dado.

Sin embargo, hay que señalar que, si bien los mapas conceptuales son empleados en la actualidad en formas y campos diferentes el propósito principal para el que fueron diseñados, según señalan Cañas y Novak (2006), continúa siendo el mismo, es decir, permitir a una o más personas representar explícitamente su entendimiento sobre un campo del conocimiento y en este sentido, los fundamentos teóricos de los mapas conceptuales no han cambiado. Por tanto, es comprensible por qué el uso de los mapas conceptuales está extendido en todos los niveles educativos (Branwell-Lalor y Rainfordb, 2014; Cantinotti, Désormeaux-Moreau, y Balbinotti, 2017; Campbell, 2016; Ibáñez y Arribas, 2012; Kinchin, 2010; 2014, Wei y Yue, 2016; 2017).

Ahora bien, Cañas y Novak (2006), con el fin de verificar cambios específicos en los conceptos de ciencias que se les enseñaban a niños y niñas, revisaron a profundidad tanto los principios de aprendizaje ausbeliano como las ideas constructivistas epistemológicas que subyacen a su trabajo, entre las cuales resaltan:

(1). El universo consiste de objetos y eventos, y la energía se intercambia durante los eventos. (2). Los conceptos son construidos por los humanos y son regularidades percibidas como patrones en eventos de objetos o registros de eventos u objetos, designada con una etiqueta, usualmente una palabra. (3). Dos o más conceptos pueden ser enlazados con palabras apropiadas para formar una declaración significativa o proposición. (4). Los conceptos y las preposiciones son los bloques de construcción del conocimiento en todos los campos (p. 2).

Entre los fundamentos clave, relacionados con el aprendizaje, que sustentan los mapas conceptuales, se pueden citar seis principios básicos: primero, el aprendizaje significativo es 
necesario para lograr el progreso en el entendimiento conceptual. En segundo lugar, el nuevo aprendizaje se debe construir a partir de conceptos o ideas previas ya existentes en el estudiante. Tercero, quien aprende debe ser motivado para que elija aprender significativamente. De lo contrario, se tratará de un aprendizaje superficial. En cuarto lugar, disponer de ayudas apropiadas para aprender conceptos abstractos, lo cual exige instrucción didáctica apropiada. En quinto lugar, el aprendizaje se considera idiosincrático. Y por último, un aprendizaje significativo y de alta calidad demanda la construcción de estructuras cognitivas que se integran eficazmente para facilitar el nuevo aprendizaje y se disponen para la solución de problemas (Cañas y Novak, 2006; Hacıoğlu, Yamak, y Kavak, 2016; Roig y Araya, 2013).

En un mapa conceptual los conceptos se pueden organizar jerárquicamente, de esta manera los conceptos de mayor generalidad ocuparán los espacios superiores y los más específicos debajo de estos, mostrando en este caso una estructura bidimensional (Aguilar, 2006; Araujo, Bueno, Almeida y Borsato, 2007). Igualmente, es posible categorizar los mapas conceptuales según su forma, de hecho a partir de las contribuciones de autores como Byme y Grace, 2010; López et al. 2014; y Rivadulla-López et al., 2016, es posible clasificarlos en tres grandes categorías:

- Araña: se presenta la palabra o concepto central y, a partir de esto, los temas de menor jerarquía se disponen alrededor.

- Red: se muestran un conjunto de conceptos relacionados o vinculados entre sí en una red integrada.

- Árbol: el concepto clave es ubicado en la parte superior del mapa, y, a partir de este, van descendiendo o asociándose el resto de conceptos subsumidos o inferiores según su importancia.

Es importante acotar, desde la teoría del aprendizaje significativo (Cañas y Novak 2006; Moreira 2012), significados idiosincráticos, de manera que los mapas conceptuales, diseñados por docentes y estudiantes, reflejen tales significados. Por consiguiente, estos mapas sea que se usen como recursos didácticos o para evaluación tendrán siempre su carácter idiosincrático (Pérez y Gutierrez. 2018).

En este orden de ideas, afirma Moreira (2012): "Lo que el alumno presenta es su mapa y lo más importante no es si ese mapa esta correcto o no, sino si da evidencias de que el alumno está aprendiendo significativamente el contenido" (p.7). Hecha la observación anterior, el papel del docente es lograr que el estudiantado internalice los significados que son 
aceptados en el contexto de la materia de enseñanza y que son compartidos por la comunidad científica (Bergan-Roller, Galt, Heliker y Dauer, 2020).

Así, adoptar los mapas conceptuales en el aula, como lo proponen Cañas y Novak (2006), exige concebirlos como un medio para construir conocimiento. Igualmente, permite comprender lo que el estudiantado piensa sobre un contenido particular, así como de brindar oportunidades para que establezcan relaciones importantes entre los conceptos abordados en las sesiones de aprendizaje (Campbell, 2016). Todo lo anterior demanda que el colectivo de docentes sea conocedor y hábil mapeador de conceptos, que sea capaz de comprender y aplicar los términos operacionales para construir un mapa y para discernir los significados idiosincráticos que le posibiliten comprender las estructuras cognitivas del estudiante que lo diseñó, y en caso de que sea necesario, proporcionar retroalimentación para jalonar hacia un mejor entendimiento conceptual (Subramaniam y Esprívalo, 2015).

\section{Materiales y métodos}

\subsection{Enfoque}

El estudio es de tipo mixto, y se desarrolló como un estudio de caso con técnicas y recolección de datos cualitativos y cuantitativos (Hernández, Fernández y Baptista, 2014). Vale agregar que el estudio de casos, como método, tiene su fundamento epistemológico en un principio comprensivo-explicativo que permite aproximarse a determinada realidad. Según lo agrega Muñiz (2010), una investigación de esta clase tiene por objeto el estudio de los fenómenos en los que participan personas, grupos, o instituciones, concebidas como unidades sujeto/objeto susceptibles que proveen información valiosa que puede utilizarse para el desarrollo de una investigación.

\subsection{Unidades de estudio}

En este estudio participaron trece estudiantes, doce niñas y un varón $(N=13)$, de quinto grado $\mathrm{C}$ de educación básica primaria, con edades que oscilan entre los 9 a 12 años y cuyas familias viven en zona rural, corregimiento de Caracolí, municipio de Malambo, departamento del Atlántico, en Colombia. Pertenecen a un estrato socioeconómico bajo, y la mayor parte de los padres se dedican a la agricultura. Nótese que se trata de una muestra teórica-estructural coherente con este tipo de investigación. Por ende, la representatividad de la muestra no recae en la cantidad o como lo señala Rojas (2014), "no obedece a criterios de representación numérica" (p. 72), sino a las posibles configuraciones subjetivas e idiosincráticas de los mapas 
y textos aportados por el grupo de estudiantes, así como la accesibilidad al momento de realización del estudio (Báez y Pérez de Tudela, 2014; Mena, 2017). El estudio fue desarrollado en el año 2017.

\subsection{Técnicas de recolección}

Como técnicas de recolección de información se empleó mapas conceptuales y entrevistas a profundidad. Para clasificar las entrevistas a profundidad se utilizaron claves así: ES501, donde los literales ES significan estudiantes, el número 5 indica el grado quinto, y los siguientes números 01 , aluden al orden asignado a la entrevista. Igualmente, para clasificar los mapas conceptuales se les asignó la misma clave agregando los literales t1 o t2 para indicar que fueron desarrollados en un tiempo pre o post, respectivamente, a la intervención del docente. En la Tabla 1 se pueden visualizar las puntuaciones dadas a los mapas conceptuales desarrollados por los estudiantes en los dos tiempos, a través de una puntuación en escala de intervalo de 1 a 12 puntos de los mapas.

Tabla 1. Puntuaciones de los mapas conceptuales desarrollados por el estudiantado pre (t1) y post

(t2) a la instrucción docente y relaciones conceptuales desarrolladas en t2. Colombia, 2017

\begin{tabular}{cccc}
\hline Estudiante & $\begin{array}{c}\text { Entendimiento } \\
\text { conceptual } \\
\text { pre (t1) }\end{array}$ & $\begin{array}{c}\text { Entendimiento } \\
\text { conceptual } \\
\text { post (t2) }\end{array}$ & \#Relaciones \\
\hline ES501 & 5 & 12 & 3 \\
ES502 & 2 & 4 & 1 \\
ES503 & 4 & 10 & 2 \\
ES504 & 4 & 12 & 3 \\
ES505 & 4 & 12 & 3 \\
ES506 & 3 & 8 & 2 \\
ES507 & 3 & 11 & 2 \\
ES508 & 7 & 12 & 3 \\
ES509 & 4 & 12 & 3 \\
ES510 & 2 & 6 & 1 \\
ES11 & 3 & 8 & 3 \\
ES12 & 4 & 6 & 2 \\
ES13 & 4 & 6 & 2 \\
\hline
\end{tabular}

Fuente: Elaboración propia a partir de los datos de las puntuaciones de los mapas del estudiantado, 2020

\subsection{Procesamiento de los datos}

Primero, se realizó un análisis cuantitativo basado en las puntuaciones obtenidas por cada estudiante en la construcción de los mapas conceptuales a partir de una rúbrica basada en el trabajo de Utria (2000) como instrumento cuantitativo. Este análisis se efectuó con el software o programa estadístico SPSS Statistic versión 25. 
En este sentido Cook (2017), afirma que los mapas conceptuales pueden utilizarse como instrumento de evaluación, sin embargo, para hacer más eficiente este proceso es necesaria la utilización de múltiples mapas previos y posteriores a la instrucción. Por tanto, se tuvieron en cuenta los datos obtenidos a través de la puntuación en escala de intervalo de 1 a 12 puntos de los mapas en un tiempo 1 (t1) y un tiempo 2 (t2). De manera que se contrastaron las puntuaciones de estos mediante la prueba de rangos de Wilconxon considerando un valor de significancia $(p<.05)$ para la aceptación de la hipótesis alterna. Mediante este proceso se pretendió dar respuesta, básicamente, al interrogante número dos: ¿En qué medida los mapas conceptuales pueden ser herramientas que permitan describir el progreso en el entendimiento conceptual logrado por los estudiantes de quinto grado $C$ de primaria de la IETAC sobre el concepto célula? En cuanto a la pregunta tres: ¿puede establecerse relación entre el progreso en el entendimiento conceptual logrado por el estudiantado y el número de relaciones conceptuales que establecen? asociada estrechamente con el primer y tercer objetivo planteado para la investigación, se utilizó el análisis del coeficiente de correlación de Spearman $r_{s}$. Vale señalar que las relaciones conceptuales se verificaron gráficamente con las flechas, que sirven de unión entre un concepto y otro, y establecen una relación conceptual correcta o válida.

Además, para concretar el primer objetivo planteado por el investigador, se desarrolló, desde un enfoque fenomenológico, la indagación sobre el entendimiento conceptual y descripción del grado de compresión del estudiantado sobre el concepto célula, durante la construcción de los mapas conceptuales, mediante sendas entrevistas realizadas. Se analizarán los aportes de los estudiantes a partir de un microanálisis línea por línea a los textos siguiendo sugerencias de Creswell (2012) y Coffey y Aktison (2003). Ahora bien, a partir de la información obtenida del estudiantado y de la literatura consultada, se caracterizó el entendimiento conceptual alcanzado desde tres categorías: organización jerárquica, diferenciación progresiva y reconciliación integradora, constituidas a partir de la teoría del aprendizaje significativo ausbeliano como sustento de la constitución de este proceso de categorización. Siguiendo con esta idea, Moreira (2012), afirma que en efecto, "los mapas conceptuales pueden utilizarse para integrar, reconciliar y diferenciar conceptos" (p. 3).

En cuanto a la categoría organización jerárquica, esta trata sobre el proceso del aprendizaje significativo mediante el cual los nuevos conceptos se engloban bajo otros conceptos más generales e inclusivos, por ende los mapas conceptuales deben ser jerárquicos, esto significa, tal como lo señalan Novak y Gowin (2002), que "Ios conceptos más 
generales e inclusivos deben situarse en la parte superior del mapa y los conceptos progresivamente menos específicos y menos inclusivos, en la inferior" (p. 33).

En el caso particular de la organización jerárquica, siguiendo a Figueroa, Utria y Colpas (2005), las características consideradas como subcategorías del entendimiento conceptual son: relaciones conceptuales generales o concretas, relaciones conceptuales sin distinción clara entre conceptos generales y concretos, y relaciones conceptuales sencillas de alto y bajo nivel.

Además de la organización jerárquica previamente considerada, la diferenciación progresiva y la reconciliación integradora hacen parte de los principios básicos del aprendizaje significativo de Ausubel (Moreira, 2012; Rivadulla-López et al., 2016). En este sentido, la diferenciación progresiva se evidencia a medida que los conceptos que interactúan con el nuevo conocimiento, y que sirven de enclaves o bases para la atribución de nuevos significados, se van modificando en función de esa interacción, "es decir van adquiriendo nuevos significados y diferenciándose progresivamente" (Moreira, 2012, p.5) o como lo señala Karip (2019), se van estructurando estableciéndose conexiones significativas. Las subcategorías consideradas dentro de la diferenciación progresiva son: asimilación de los significados de los conceptos, reconocimiento de nuevas relaciones conceptuales y reorganización de la estructura cognoscitiva (Figueroa et al., 2005).

Ahora bien, la diferenciación y la reconciliación integradora constituyen dos procesos interrelacionados. De hecho, según lo señala Moreira (2012), "Todo aprendizaje que resulte en una reconciliación integrativa resultará también en una diferenciación progresiva adicional de conceptos y proposiciones" (p. 6). Específicamente, la categoría reconciliación integradora ocurre con el establecimiento de relaciones entre ideas, conceptos o proposiciones ya establecidas en la estructura cognitiva. (Figueroa et al., 2005; Moreira, 2012).

Las características asociadas a la reconciliación integradora son: relaciones de conceptos no apropiadas, relaciones memorísticas y relaciones significativas (Figueroa et al., 2005). La Tabla 2 resume las categorías y subcategorías utilizadas para la caracterización del entendimiento conceptual y las puntuaciones dadas a cada una de estas, que permitieron puntuar los mapas construidos por el grupo de estudiantes. 
Tabla 2. Estructura de categorías y subcategorías para la caracterización del entendimiento conceptual de los estudiantes de quinto grado de la IETAC. Colombia, 2017

\begin{tabular}{ccc}
\hline Categorías & Subcategorías & Puntuación \\
\hline Organización jerárquica & $\begin{array}{c}\text { Relaciones conceptuales } \\
\text { generales o concretas } \\
\text { Relaciones conceptuales sin } \\
\text { distinción } \\
\text { Relaciones conceptuales } \\
\text { sencillas }\end{array}$ & 1 \\
Diferenciación progresiva & $\begin{array}{c}\text { Relaciones conceptuales } \\
\text { complejas }\end{array}$ & 2 \\
& $\begin{array}{c}\text { Asimilación de significados } \\
\text { de conceptos }\end{array}$ & 1 \\
Reconociliación integradora & $\begin{array}{c}\text { Reconto de nuevas } \\
\text { relaciones conceptuales } \\
\text { Reorganización de la } \\
\text { estructura cognoscitiva } \\
\text { Relaciones de concepto no } \\
\text { apropiadas }\end{array}$ & 2 \\
& $\begin{array}{c}\text { Relaciones memorísticas } \\
\text { Relaciones significativas }\end{array}$ & 1 \\
\hline
\end{tabular}

Fuente: Elaboración propia, 2020

Con referencia a la construcción de cada mapa conceptual, se llevó a cabo durante una hora aproximadamente, tomada del tiempo asignado en el horario escolar a la asignatura de Ciencias Naturales, esto es cinco horas semanales. Para ello, fue necesario por un lado, instruir al grupo de participantes sobre la construcción de los mapas conceptuales e implementar, las sugerencias de Novak y Gowin (2002), y por otro, entrenar con el estudiantado los pasos sugeridos por Campbell (2016), así como las técnicas de construct- a map o mapa abierto y de fill- in map o mapa cerrado, referenciadas por Hermosillo y González (2012). Adicionalmente, para orientar al grupo estudiantil sobre la construcción de mapas conceptuales, se utilizaron como ejemplos conceptos que ya habían sido internalizados por los estudiantes en grados anteriores

Después de lograr que el grupo se familiarizara con la construcción de mapas, se les propuso construir uno inicial sobre el concepto. Esto demandó planear y desarrollar sesiones de enseñanza sobre el concepto célula, enmarcada en estrategias socio-constructivistas. Es importante señalar que durante el desarrollo de las sesiones y la construcción de los mapas se promovió un ambiente cordial y de respeto. Los mapas realizados en el tiempo 1 y el tiempo 2 fueron desarrollados en papel para su posterior análisis. 


\section{Resultados}

La fase caracterizada por la aplicación de procedimientos cuantitativos se implementó para poder apuntar hacia el primer objetivo planteado y poder responder al interrogante numero dos sobre la efectividad de los mapas conceptuales y dar cuenta del entendimiento del concepto célula. Se determinó mediante la prueba de Shapiro Wilk, con un nivel de significación de .05 la normalidad de las variables $t_{1}$ y $t_{2}$, así como la diferencia entre estas, obteniendo que $(\mathrm{p}<.05)$. Por consiguiente, se deduce que tanto $t 1, t 2$, así como la diferencia entre estas medidas no tiene distribución normal. En la Tabla 3, se aprecian los resultados estadísticos mencionados anteriormente.

Tabla 3. Prueba de normalidad de las variables y la diferencias de entendimiento conceptual pre $\left(t_{1}\right)$ y post $\left(t_{2}\right)$ logrado por los estudiantes de quinto grado $C$ de la IETAC. Colombia, 2017

\begin{tabular}{cccc}
\hline Variables & Estadístico & $\begin{array}{c}\text { Shapiro-Wilk } \\
\text { Grados } \\
\text { de } \\
\text { libertad }\end{array}$ & Valor $p$ \\
\hline$t_{1}$ & .868 & 13 & .049 \\
$t_{2}$ & .844 & 13 & .024 \\
Diferencias $\left(t_{2}-t_{1}\right)$ & .864 & 13 & .044 \\
\hline
\end{tabular}

Fuente: Elaboración propia, con los datos recolectados de las puntuaciones de los mapas del estudiantado, 2020

En consecuencia, para establecer la significancia estadística entre la variación de las medidas tomadas en $t_{1}$ y en $t_{2}$, se utilizó la prueba no paramétrica de rangos Wilconxon para medidas relacionadas. Se planteó el problema mediante las hipótesis:

$H_{0}=$ las medias de las puntuaciones de los mapas de los estudiantes después y antes de la intervención docente no difieren entre sí

$H_{1}=$ las medias entre las puntuaciones de los mapas antes y después de la intervención docente difieren entre sí.

El resultado que se puede apreciar en la Tabla 3 indica que la hipótesis alterna $H_{1}$ es válida y determina que sí existe diferencia significativa entre las medias de la realización de los mapas conceptuales del $t_{1}$ y $t_{2}(\mathrm{z}=-3.197, \mathrm{p}<.05)$. Asimismo, el análisis de los estadísticos descriptivos muestra que las medias del $t_{1}$ son menores que el $t_{2}$, esto puede visualizarse en la Tabla 4. Lo anterior significa que los mapas conceptuales evidencian un incremento del entendimiento del concepto célula por parte de los estudiantes después de la instrucción. En la tabla 4 y 5 es posible apreciar los resultados de análisis de los estadísticos descritos anteriormente. 
Tabla 4. Prueba de rangos de Wilconxon de la diferencia entre entendimiento conceptual post $\left(t_{2}\right)$ y pre $\left(t_{1}\right)$ de los estudiantes de quinto grado C de la IETAC. Colombia, 2017

\begin{tabular}{|c|c|c|c|c|}
\hline & \multicolumn{4}{|c|}{ Prueba de rangos con signo de Wilcoxon } \\
\hline \multirow{6}{*}{$t_{1}-t_{2}$} & & & ngos & \\
\hline & & $\mathrm{N}$ & Rango promedio & Suma de rangos \\
\hline & $\begin{array}{l}\text { Rangos } \\
\text { negativos }\end{array}$ & $0^{\mathrm{a}}$ & 0 & 0 \\
\hline & $\begin{array}{l}\text { Rangos } \\
\text { positivos }\end{array}$ & $13^{b}$ & 7.00 & 91.00 \\
\hline & Empates & $0^{c}$ & & \\
\hline & Total & 13 & & \\
\hline
\end{tabular}

\section{Estadísticos de prueba ${ }^{a}$}

t2-t1

$-3.197^{d}$

$.001^{\mathrm{e}}$

Sig. asintótica(bilateral)

Fuente: Elaboración propia, con los datos de las puntuaciones de los mapas del estudiantado, 2020

${ }^{\mathrm{a}} t_{2}<t_{1}$

b $t_{2}>t_{1}$

${ }^{\mathrm{c}} t_{2}=t_{1}$

d Prueba de rangos con signo de Wilcoxon

e Se basa en rangos negativos

Tabla 5. Estadísticos descriptivos de las medias entre el entendimiento conceptual pre (t1) y post (t2) logrado por los estudiantes de quinto C de la IETAC. Colombia, 2017

\begin{tabular}{lrrrrr}
\hline \multicolumn{7}{c}{ Estadísticos descriptivos } \\
\hline $\mathrm{N} 1$ & $\mathrm{~N}$ & Mínimo & \multicolumn{1}{c}{ Máxim } & Media & $\begin{array}{c}\text { Desv. } \\
\text { Desviación }\end{array}$ \\
$\mathrm{t} 2$ & 13 & 2 & 7 & 3.77 & 1.30 \\
Diferencias (t2-t1) & 13 & 4 & 12 & 9.15 & 2.94 \\
$\mathrm{~N}$ válido (por lista) & 13 & 2.00 & 8.00 & 5.38 & 2.36 \\
\hline
\end{tabular}

Fuente: Elaboración propia, a partir de análisis estadísticos, 2020

Se percibe que los y las estudiantes con puntajes bajos en los mapas exhibieron una tendencia a desarrollar relaciones conceptuales generales y en un solo nivel de jerarquía. En contraste, los mapas de estudiantes con puntajes altos, evidenciaron que aunque establecen relaciones generales, tienden a desarrollar distintos niveles de jerarquía entre conceptos. Por lo menos tres o cuatro de ellos, establecen relaciones y distinciones entre conceptos generales y otros específicos, de forma más adecuada que los estudiantes con puntajes bajos.

Para corroborar tal hecho se realizó un análisis de correlación de Spearman $r_{s}$, entre la variable $t_{2}$, y la variable relaciones complejas desarrolladas por los estudiantes en este 
segundo mapa. Esto dado, que se trata de datos que presentaron comportamiento no paramétrico, y puesto que se trató, como ya se ha dicho, de una muestra poco potente desde el punto de vista estadístico. Se planteó el problema estadísticamente para este caso así:

$H_{0}=$ no existe correlación entre el entendimiento conceptual post $\left(t_{2}\right)$ y el número de relaciones conceptuales desarrolladas en los mapas en $t_{2}$.

$H_{1}=$ existe correlación entre la variable entendimiento conceptual post $\left(t_{2}\right)$ y el número de relaciones conceptuales en los mapas en $t_{2}$.

Los resultados ponen de manifiesto que existe una asociación significativa entre el entendimiento conceptual logrado en el $t_{2}$ y el número de relaciones complejas que se establecen en dicho momento ( $r=.807, n=13, p=.001)$. Por consiguiente, se puede verificar que existe una relación entre el desarrollo del entendimiento conceptual logrado por los estudiantes después de la instrucción y el número de relaciones conceptuales establecidas por estos en sus mapas desarrollados después de dicha intervención (Tabla 6).

Tabla 6. Correlación de Pearson entre variable entendimiento conceptual post y numero de relaciones conceptuales desarrolladas por los estudiantes de quinto de la IETAC en t2. Colombia, 2020

Correlaciones

\begin{tabular}{|c|c|c|c|}
\hline 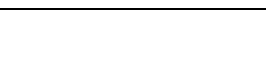 & & & Relaciones \\
\hline \multirow[t]{6}{*}{ Rho de Spearman } & $t_{2}$ & $\begin{array}{l}\text { Coeficiente de } \\
\text { correlación }\end{array}$ & $.846^{\dagger}$ \\
\hline & & Sig. (bilateral) & .000 \\
\hline & & $\mathrm{N}$ & 13 \\
\hline & Relaciones & $\begin{array}{l}\text { Coeficiente de } \\
\text { correlación }\end{array}$ & .846 \\
\hline & & Sig. (bilateral) & \\
\hline & & $\mathrm{N}$ & 13 \\
\hline
\end{tabular}

${ }^{\mathrm{f}}$ La correlación es significativa en el nivel 0,01 (bilateral

Fuente: Elaboración propia, a partir de resultado de análisis estadístico, 2020

\subsection{Hallazgos desde lo cualitativo}

A continuación se exponen los hallazgos obtenidos a partir del microanálisis efectuado línea por línea a los textos aportados por el grupo de estudiantes mediante la entrevista en profundidad (Coffey y Atkisson, 2003; Creswell, 2012). Al hacer lectura de los comentarios de los estudiantes se percibe que aquellos que obtuvieron altos puntajes en el $t_{2}$ desarrollaron mayor número de relaciones complejas, en contraste con los estudiantes que obtuvieron bajos puntajes. 


\subsubsection{Organización jerárquica}

En general, los estudiantes con puntuaciones bajas en los mapas, en el tiempo 2, presentan un entendimiento insuficiente del concepto, por cuanto no han logrado distinguir las relaciones entre célula y sus orgánulos, o entre la célula y los seres vivos. En cambio, los estudiantes con puntuaciones altas han logrado establecer relaciones entre la célula y otros conceptos, tales como procariotas y eucariotas, unicelulares y pluricelulares, autótrofos y heterótrofos, bacterias, plantas, entre otros. $Y$ aunque las relaciones que establecen son simples, se perciben las jerarquías que establecen entre estos.

Para ilustrar, una estudiante con puntaje alto agrega:

"la célula es un microorganismo que tiene núcleo, citoplasma y membrana y la célula es necesaria para todos los seres vivos, porque todos los seres vivos tienen célula... la célula puede ser animal y vegetal y son diferentes" (ES53)

En este caso, se observa cómo establece jerarquía entre el concepto célula y el de los orgánulos celulares o las partes esenciales de toda célula, esto se visualiza en los dos niveles que muestra en su mapa.

\subsubsection{Diferenciación Progresiva}

Se evidencia diferenciación progresiva en el entendimiento conceptual logrado por el grupo participante en el $t_{2}$ en contraste con el $t_{1}$, al verificar asimilación de los significados de conceptos como: unicelular y pluricelular, eucariota y procariota, entre otros. Asimismo, reconocimiento de nuevas relaciones conceptuales al relacionar estos conceptos nuevos con el concepto célula. Igualmente, en la subcategoría reorganización de las estructuras cognitivas se evidencia cómo una parte del grupo de estudiantes empiezan a concebir que las células tienen características comunes y diferentes según la clase de ser vivo que se considere. Para ejemplificar tal proceso, observe el siguiente texto: "la célula de las plantas tienen clorofila por eso es verde y hace su propio alimento, y la animal no" (ES54).

También en este otro comentario, es posible verificar cómo el aprendiz diferencia varios conceptos asociados con el concepto central estudiado, es decir, la célula. Igual de significativa es la capacidad del aprendiz para ilustrar lo que relaciona o asocia

La célula es la parte más pequeña que tiene un ser vivo y se divide en dos partes: procariota o eucariota. Procariota cuando no tienen núcleo, y eucariota cuando tienen núcleo. Ejemplo de células procariotas las bacterias y de eucariotas los seres vivos, los humanos (ES511). 
De la misma forma, se verifica diferenciación progresiva y reorganización cognitiva en comentarios como: "La célula es la parte más pequeña de un ser vivo. Los seres vivos pueden ser pluricelulares, significa que tienen muchas células y unicelulares significa que tiene una célula" (ES59, comunicación personal, 4 de mayo, 2017). En contraste, una estudiante con puntajes bajos comenta: "La célula es núcleo, citoplasma, mitocondria, la célula es la bacteria... el núcleo es como una pared que mantiene a la célula" (ES57, comunicación personal, 4 de mayo, 2017).

Este comentario evidencia poca claridad respecto al concepto y poca diferenciación entre varios conceptos relacionados, tales como núcleo y orgánulos, así como bacterias.

\subsubsection{Reconciliación integradora}

Entre las características y, a su vez, subcategorías relacionadas con la reconciliación integradora que caracterizan el entendimiento conceptual de los participantes se encontraron: relaciones no apropiadas entre conceptos como: relaciones memorísticas y relaciones significativas. En cuanto a las relaciones memorísticas, es posible rastrear comentarios como: "la célula es núcleo, citoplasma, mitocondria. La célula es eh... este unas bacterias" (ES57, comunicación personal, 4 de mayo, 2017). En este caso, la estudiante no ha internalizado o conceptualizado significativamente el concepto célula. Por tanto, no lo diferencia, no es capaz de describir las relaciones de este con otros conceptos como bacterias o procariotas 0 eucariotas, y se limita simplemente a una definición memorística que ha escrito en su mapa.

El no desarrollar una adecuada diferenciación del concepto impide establecer reconciliaciones entre las estructuras o ideas previas que tenía de la célula y las que se requieren o son deseadas para poder lograr el entendimiento conceptual adecuado. En contraste, una estudiante con alta puntuación en sus mapas evidencia que ha establecido relaciones entre los conceptos nuevos, como eucariota, procariota y la célula, al señalar: "la célula se divide en eucariota y procariota. Eucariota significa que tienen núcleo y procariota significa que no tienen núcleo" (ES510). Destacar que estas últimas relaciones significativas fueron menos desarrolladas por colectivo estudiantil y estuvieron presentes solo en los mapas conceptuales que obtuvieron los puntajes más altos es interesante.

Es posible verificar el progreso de la reconciliación integradora al comparar las relaciones establecidas por un mismo participante al considerar los mapas desarrollados sobre el concepto célula para los dos tiempos. En el caso de los estudiantes con puntajes altos, se observó, tal como se comprobó con el análisis correlacional, la tendencia a desarrollar nuevo 
tipo de relaciones, es decir, asociar conceptos que ya forman parte de su estructura cognitiva con el concepto célula, lo cual se hace evidente en el mayor número de relaciones apropiadas y jerarquías establecidas en su mapa del t2 en contraste con el t1.

A modo de ilustración, los siguientes mapas conceptuales de un grupo de estudiantes que logró altos o bajos puntajes en los mapas, son evidencia de progresos o dificultades en el entendimiento conceptual según sea el caso. En la Figura 1 y posteriormente, en Figura 2, se visualizan, respectivamente, los mapas desarrollados por un estudiante con puntuación alta, y se contrastan durante el $\mathrm{t} 1 \mathrm{y}$ t2.

Figura 1. Mapa conceptual elaborado por un estudiante de quinto grado $\mathrm{C}$ de la IETAC (ES50t1), sobre el concepto célula en el t1

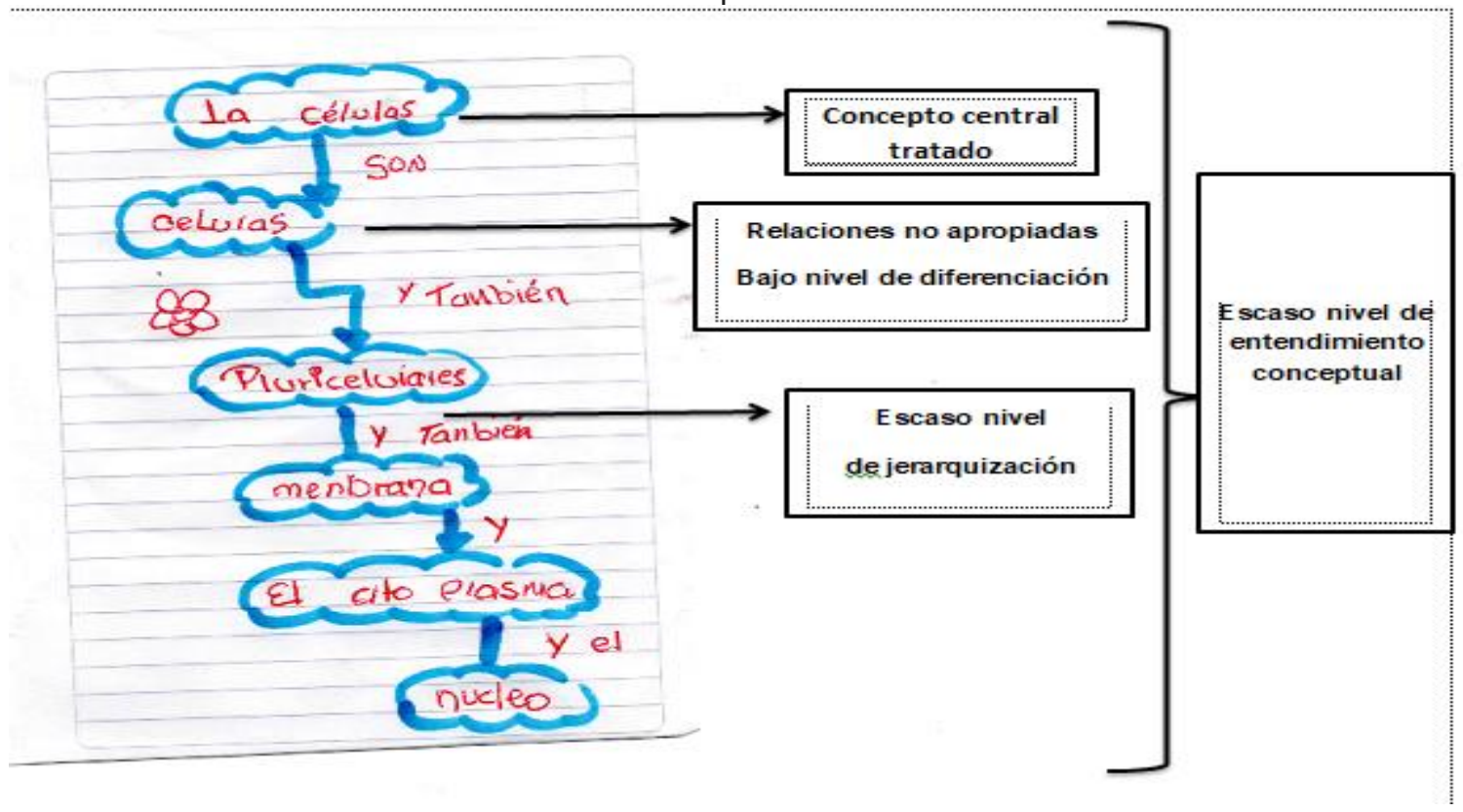

Fuente: Elaboración propia a partir de mapa conceptual diseñado por una estudiante, 2020.

En este primer ejemplo, en el mapa t1 de la estudiante ES5010, se evidencia que el mapa es del tipo árbol según lo señalado por Rivadulla-López, et al. (2016), o también llamado lineal según López et al. (2014), este mapa sigue la estructura de ubicar el concepto central en la parte superior y los conceptos relacionados debajo. Tal estructura es común a la mayoría de los mapas analizados para los dos tiempos. sin embargo, en este mapa t1, se percibe que el estudiante tiene poco entendimiento conceptual sobre la célula, en este caso hay ausencia de definición de atributos del concepto, y vale resaltar que es una característica común a todos los mapas elaborados por los participantes en el primer momento. 
Otra característica común en los mapas elaborados en el $\mathrm{t} 1$, es que el total de los estudiantes establecen una relación entre célula- membrana-núcleo-citoplasma. Sin embargo, como se corrobora mediante las entrevistas, se trata de una relación memorística, puesto que no eran capaces de relacionar las partes elementales de la célula con alguna de sus funciones. Asimismo, los conectores utilizados para establecer la relación no son muy apropiados. En la mayoría de los casos no se establecen relaciones con los seres vivos como tales, así se observa en la Figura 1, y es una tendencia generalizada en los mapas del grupo de estudiantes.

En el caso de la Figura 2, se muestra el mapa desarrollado por la misma estudiante de la Figura 1 después de la intervención docente. A primera vista se contrasta con su progreso conceptual mediante las relaciones significativas que establece con otros conceptos. Esto se manifiesta en los diferentes niveles de jerarquía que establece en su mapa del t2. Aunque, evidentemente, la estructura del mapa sigue siendo de árbol, con el concepto de célula central y en la parte superior, se pueden diferenciar cinco niveles de jerarquía establecidos, lo cual es posible porque ha establecido relaciones apropiadas entre el concepto célula y otros conceptos. 
Figura 2. Mapa conceptual elaborado por estudiante de quinto C de la IETAC (ES50t2), sobre el concepto célula en el t1

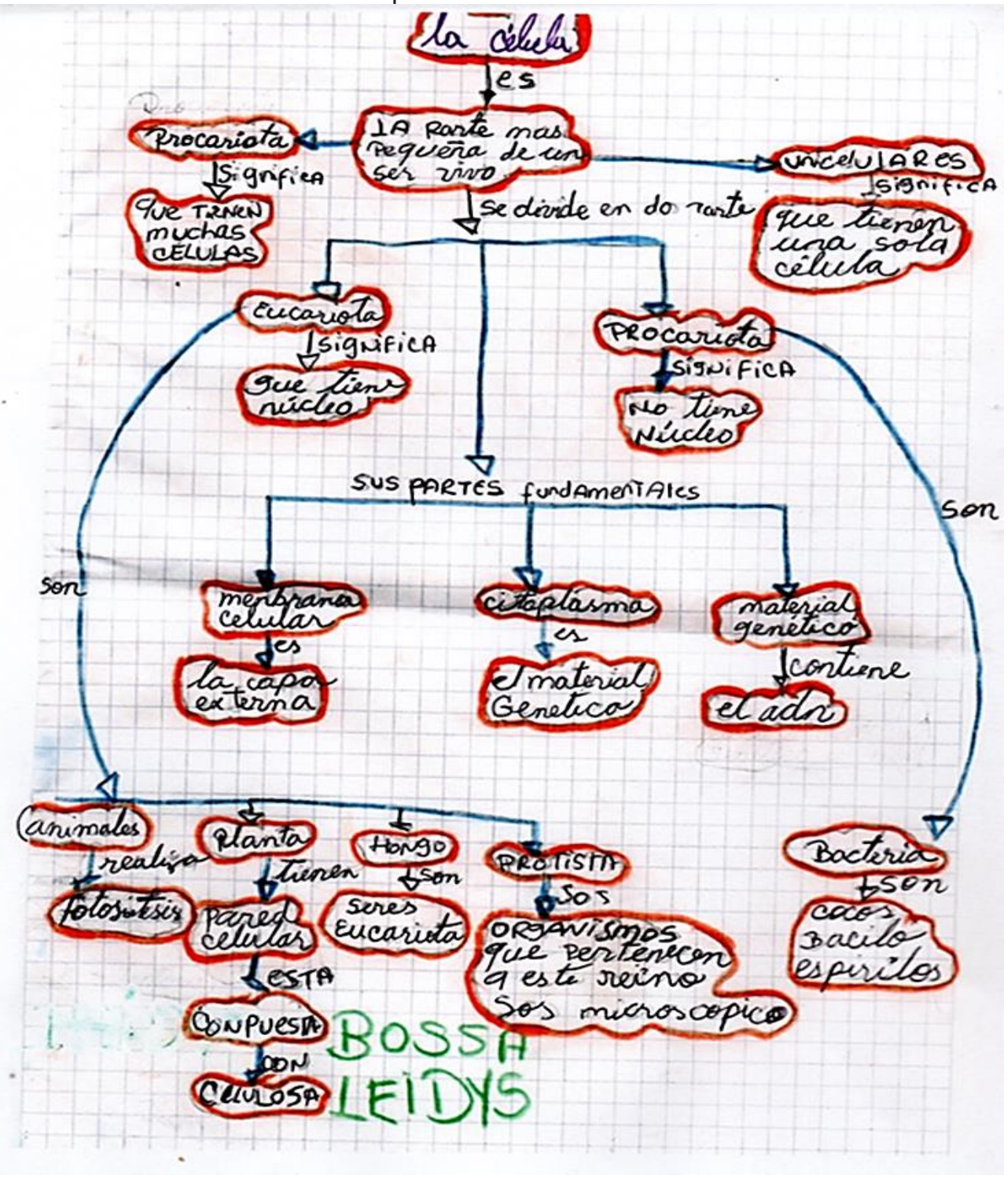

Fuente: Elaboración propia a partir de mapa conceptual diseñado por una estudiante 2020.

Igualmente, tanto en este como en la mayoría de los mapas desarrollados en el t2 por el estudiantado con un nivel de entendimiento adecuado y con puntajes altos, hay definición de atributos del concepto célula. En este caso, la definen como la parte más pequeña del ser vivo. De esta manera, se visualizan relaciones semánticas apropiadas y de alto nivel, manifestando con ello relaciones conceptuales apropiadas y un nivel de diferenciación progresiva mayor al del t1 considerado escaso. 
En la Figura 3, se observa que entre los mapas desarrollados por el estudiante no hubo cambios significativos, esto al no establecer nuevas relaciones entre conceptos. Igualmente, persistieron relaciones no apropiadas o memorísticas, particularmente, ausencia de atribuciones de significado al concepto célula, y la definió como formada por núcleomembrana-citoplasma, pero desconoce las relaciones entre estos orgánulos celulares esenciales.

Figura 3. Mapas desarrollados pre y post a la intervención docente por estudiante (ES506t1 y ES506t2), que tipifican poco entendimiento conceptual

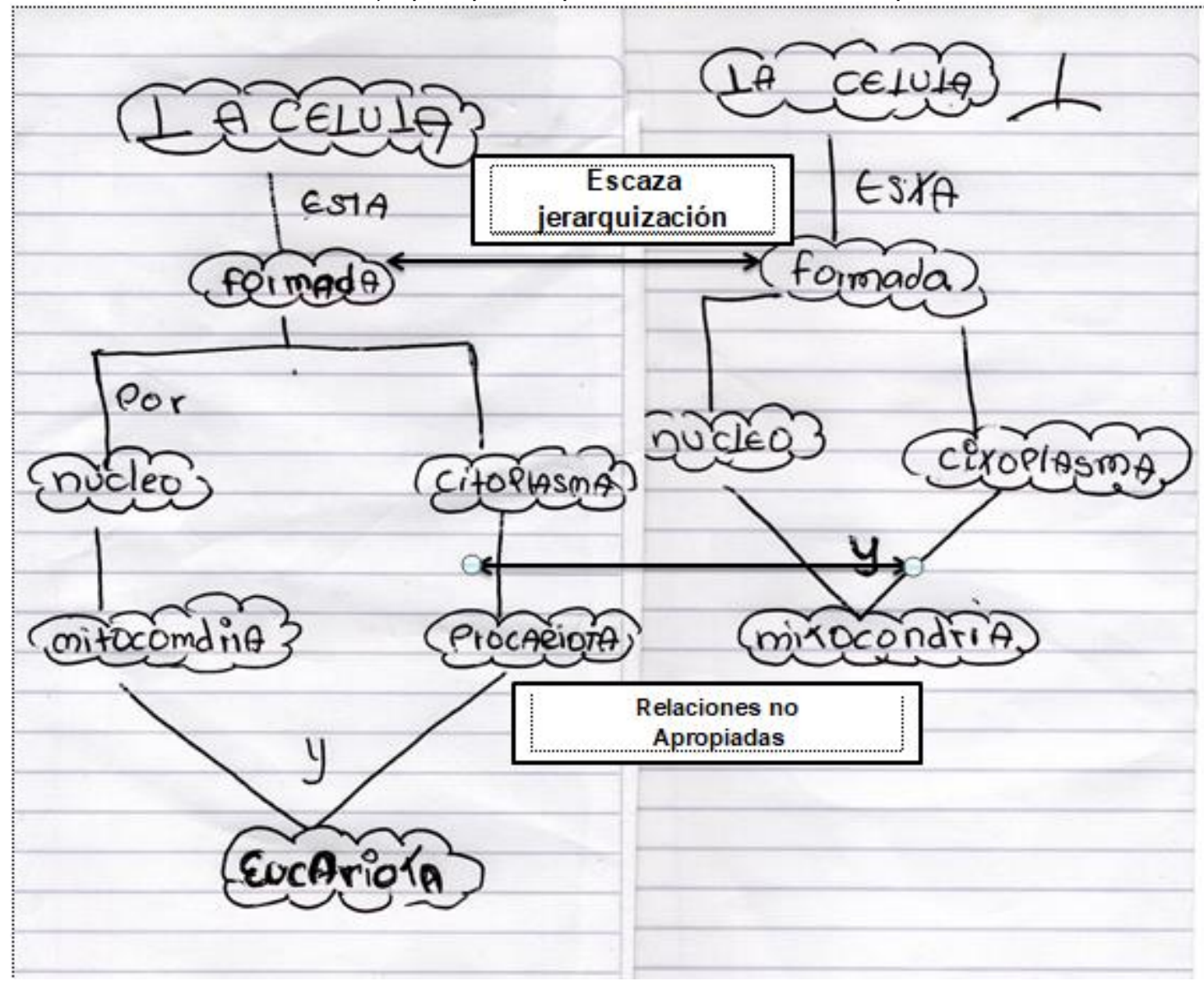

Fuente: Elaboración propia a partir de mapa conceptual diseñado por un estudiante 2020.

En consecuencia, las unidades de significado de estos mapas tienen un nivel bajo, y esta es una característica común a todos los mapas del estudiantado que exhibió dificultades en el entendimiento conceptual, manifestado con las bajas puntuaciones asignadas a los mapas conceptuales desarrollados por este grupo estudiantil. 
En la Figura 4, se percibe, de igual manera, progresos entre los mapas conceptuales del t1 y t2 de la estudiante ES503, al establecer mayores niveles de jerarquización, nuevos conceptos, nuevas relaciones conceptuales y ejemplos en el t2, lo cual evidencia mayores niveles de diferenciación conceptual. Por ejemplo, en el mapa del t1, se establecen tres niveles de jerarquización 1) se inicia con el concepto célula, luego 2) clasificación de seres vivos según sean unicelulares o pluricelulares, 3) posteriormente, clases de células según sean procariotas o eucariotas, y 3) finalmente, partes fundamentales de la célula. En el mapa del t2, en contraste, se establecen cuatro niveles de jerarquía y se incluyen aparte de los ya enunciados, la ejemplificación tanto de seres procariotas como eucariotas

Figura 4. Mapas desarrollados pre y post a la intervención docente por estudiante (ES503t1 y ES503t2), que tipifican mayores niveles de jerarquización, diferenciación progresiva y entendimiento conceptual al contrastar los $\mathrm{t} 1$ y $\mathrm{t} 2$

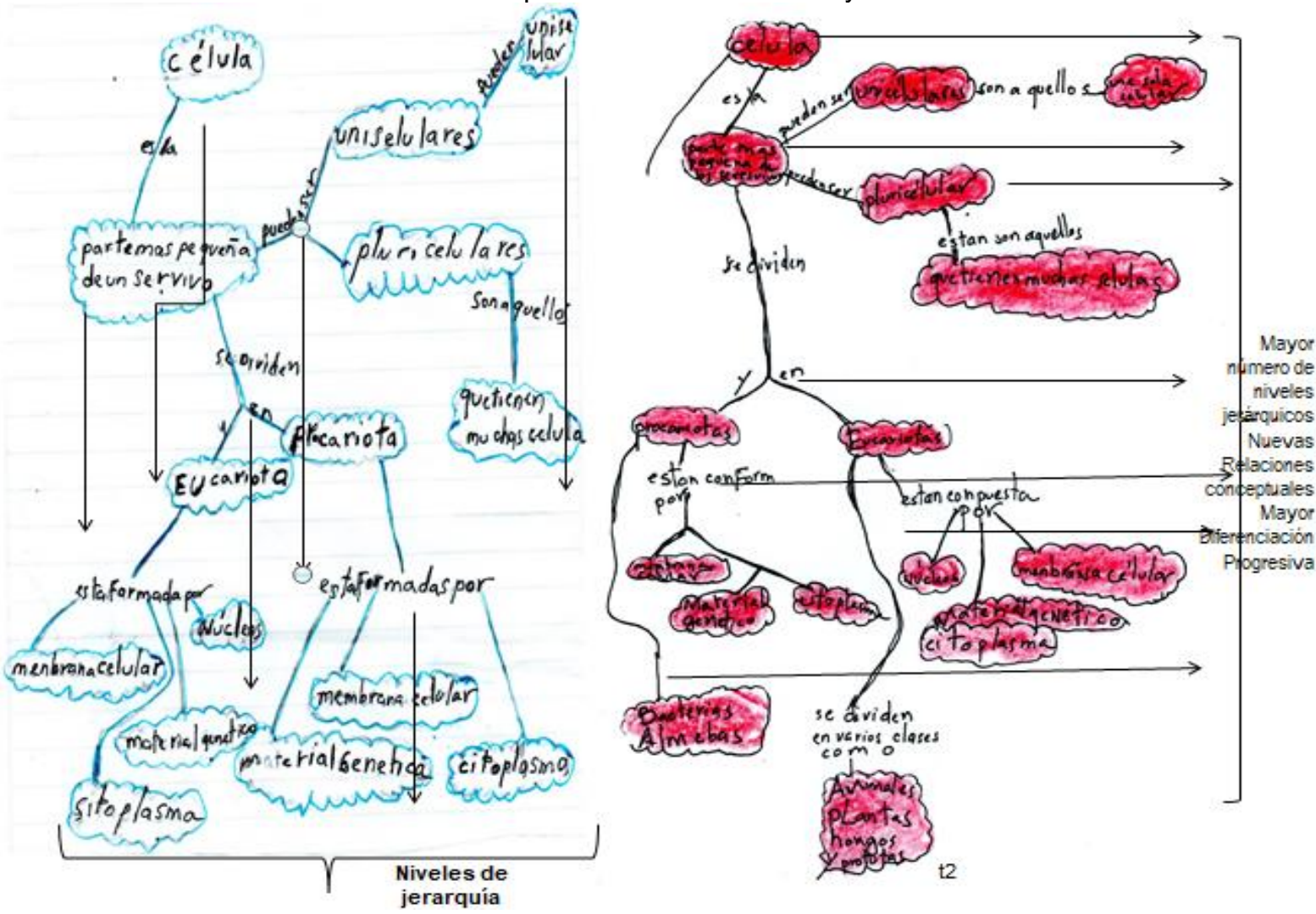

Fuente: Elaboración propia a partir de mapas conceptuales diseñados por una estudiante, 2020. 


\section{Análisis de hallazgos}

Inicialmente, las pruebas estadísticas demostraron que el entendimiento conceptual de los estudiantes sobre la célula se vio incrementado en el tiempo 2, en contraste con el tiempo 1, lo cual corrobora que los mapas conceptuales son apropiados para verificar este constructo del aprendizaje significativo. En este orden de ideas, se confirman conclusiones de las investigaciones referenciadas inicialmente con respecto a la incidencia positiva del empleo de los mapas conceptuales en el aprendizaje de conceptos científicos (Campbell 2016; Cañas y Novak 2006; Figueroa, Utria y Colpas 2006; Hermosillo y González, 2012; Moreira, 2012; Novak y Gowin, 2002; Sellmann, et al. 2015)

Al usarse, antes de la mediación del docente, los mapas junto con las entrevistas en profundidad permitieron explorar las ideas previas y los errores conceptuales de los estudiantes con respecto al concepto célula. Como resultado de estos hallazgos se confirma, tal como lo anotan Sellmann et al. (2015), que los mapas conceptuales son herramientas útiles para revelar las concepciones que tienen los estudiantes al ingresar a un aula, pero también permitieron identificar las estructuras de pensamiento que desarrollaron a lo largo del tiempo de instrucción (Tripto, Zvi Assaraf y Amit, 2018). En palabras de Novak y Gowin (2002), "los mapas conceptuales desarrollados por los participantes proporcionaron "un resumen esquemático de todo lo que se ha aprendido" (p.33).

En este sentido, las ideas previas de los estudiantes convergen, en su mayoría, con definir la célula en función de sus partes esenciales membrana- núcleo- citoplasma. Sin embargo, se trata de una relación memorística, puesto que no son capaces de describir, desde su nivel de escolaridad, la relaciones, por ejemplo, funcionales, que se establecen entre la célula y dichas partes. De allí que, se puede acotar que los mapas conceptuales pueden ser usados tanto para una evaluación diagnóstica, que devele las ideas previas de los estudiantes sobre un tópico particular (Pineda y Afanador, 2015; Sellman et al. 2015), así como para verificar el incremento del entendimiento conceptual después de la mediación del docente.

En cuanto a la caracterización de entendimiento conceptual, se puede afirmar que se observó que el grupo de estudiantes cuyos mapas tenían puntuaciones bajas se relacionaron con alcanzar poco entendimiento del concepto célula, evidenciado en los mapas y en las entrevistas por su tendencia a desarrollar relaciones de significados o semánticas de bajo nivel, lo que indica, a su vez, relaciones conceptuales sin distinción clara entre conceptos generales y específicos. 
Este grupo de estudiantes desarrollaron mapas en donde no se distinguen claramente niveles jerárquicos entre los conceptos abordados, lo cual es evidencia, según lo señala Moreira (2012), de que han logrado poca interacción entre sus ideas previas y las que se han desarrollado en la instrucción docente, es decir, el aprendizaje significativo del concepto célula no se ha verificado como exitosamente.

Igualmente, los niveles de diferenciación progresiva de este grupo de estudiantes se hacen explícitos en su poca asimilación de los significados de los conceptos, y, en consecuencia desarrollan un nivel bajo de relaciones conceptuales graficados en sus mapas. De modo similar, se evidencia la escaza reorganización de su estructura cognitiva. En efecto, por ejemplo, no distinguen entre el concepto de célula y orgánulos celulares, o confunden las funciones básicas de los componentes celulares esenciales.

En contraste, estudiantes con altas puntuaciones en sus mapas exhiben una organización jerárquica progresiva al comparar entre en $\mathrm{t} 1$ y t2, es decir, aunque establecieron relaciones generales, también desarrollaron relaciones de discriminación entre un concepto general y uno menos inclusivo, lo cual evidencia un nivel de progreso en el grado de entendimiento conceptual, hecho que va en la misma línea de resultados de investigaciones como las de Figueroa et al. (2006), y Pineda y Afanador (2015).

Por ello en primer lugar, es posible verificar en los mapas desarrollados por este grupo de estudiantes, que establecen diferentes niveles de jerarquía. Por ejemplo, bajo el concepto célula subsumieron conceptos tales como unicelulares, pluricelulares, y, a su vez, bajo estos otros conceptos como bacterias, animales y plantas respectivamente. En otras palabras, su nivel de jerarquización conceptual es evidente.

En segundo lugar, en cuanto a la diferenciación progresiva, la tendencia en el estudiantado con altos puntajes en sus mapas, se inclina hacia reconocer nuevos conceptos, como procariota, eucariota, autótrofos, unicelular, o pluricelular, material genético. Es decir, han logrado una mayor especificidad de significados y conceptos, lo cual, según Ausubel, Hanesian y Novak (1983), indica que este grupo de estudiantes ha internalizado o aprendido de forma significativa el concepto abordado.

En tercer lugar, respecto a la reconciliación integradora, característica de un entendimiento conceptual significativo, y que en un mapa conceptual se representan mediante los entrecruzamientos, se percibió que el grupo de estudiantes con puntuaciones bajas no desarrolló este tipo de relaciones. En contraste, aquellos con puntuaciones altas desarrollaron mayor número de entrecruzamientos. 
Adviértase que los entrecruzamientos no fueron muy comunes. Los hallazgos convergen con los de Pineda y Afanador (2015), quienes señalan que la mayoría de los estudiantes tienen dificultades en comprender las relaciones entre las estructuras celulares y sus funciones. Por ello, aquellos estudiantes con puntuaciones bajas en sus mapas, no efectuaron entrecruzamientos conceptuales a diferencia del grupo de estudiantes que establecieron nuevas relaciones. Tal es el caso, de un grupo de estudiantes que reconoció a la célula como contenedora del material genético. En la figura 3, se ejemplifica un contraste de los mapas desarrollados en los dos tiempos por un estudiante con dificultades en el entendimiento conceptual del concepto célula, y en consecuencia una baja puntuación.

\section{Consideraciones finales}

En este aparte se busca apuntar, finalmente, al cuarto objetivo planteado dentro de la investigación llevada a cabo. Como resultado de un proceso de reflexión por parte de la persona cognoscente y a partir de los resultados cualitativos y su posterior análisis se desarrollaron las siguientes consideraciones:

Los mapas conceptuales son construcciones de cada sujeto que representan el resultado de su cognición, de tal modo que plasman, mediante palabras o preposiciones, relaciones, correlaciones e interrelaciones, y jerarquías entre conceptos y procesos.

Como estrategias de aprendizaje los mapas conceptuales exigen de práctica y de una adecuada orientación acerca de su construcción. Solo de esta manera es posible su uso para apoyar los procesos de comprensión que desarrolla el estudiantado.

Los mapas conceptuales combinados con entrevistas a profundidad son efectivos para usarlos en la evaluación diagnóstica o en explorar las ideas previas de quienes aprenden. Por cuanto tienen un carácter idiosincrático, permiten develar no solo las concepciones o ideas previas del estudiantado con respecto al concepto estudiado, sino aproximarse a la estructuración cognitiva desarrollada por cada uno de ellos sobre este concepto.

Igualmente, se constata que los mapas conceptuales junto con entrevistas a profundidad permiten dar cuenta de las características del entendimiento conceptual logrado por un grupo estudiantil. Es decir, permiten al docente verificar si uno o una estudiante logró un cambio conceptual, o lo que es lo mismo desde la teoría ausbeliana, verificar si aprendió o no significativamente un concepto. Para ello, es necesario leer los mapas a la luz de las categorías emergidas de la teoría de aprendizaje significativo, tales como: jerarquización, diferenciación progresiva y reconciliación integradora. 
Por esta razón, es importante que el profesorado particularmente de Ciencias, considere seriamente el uso intencional de los mapas como herramientas de exploración, consolidación y evaluación de aprendizajes.

\subsection{Limitaciones del estudio}

Es necesario reconocer las limitaciones del estudio, las cuales radican, básicamente, en la muestra reducida: un curso de trece estudiantes $(n=13)$, dado que desde un punto de vista positivista resulta de escasa potencia estadística, y, en consecuencia, no es posible generalizar los resultados. Sin embargo, es justo advertir que esta no ha sido la pretensión de este trabjo. En contraste, se trató de un estudio de caso que se desarrolló desde un paradigma interpretativo-cualitativo o emergente, y ofreció la oportunidad de trabajar con una muestra teórico-estructural que posibilitó la descripción y comprensión del entendimiento conceptual del estudiantado desde un marco fenomenológico, ello concedió mayor aproximación de este entendimiento desde las voces de los propios estudiantes.

En este mismo orden, ha de reconocerse que la escala de puntuación asignada a los mapas conceptuales aportados por el estudiantado en los dos tiempos estuvo a cargo del docente de grupo, quien, además, desarrolló todas las asignaturas propuestas por el proyecto educativo institucional de la IETAC y exigidas por la Ley general de educación 115 de Colombia, publicada por el Ministerio de Educación Nacional ([MEN], 1994). Por tanto, es posible que, desde un paradigma eminentemente positivista, este hecho induzca a sesgos dentro del proceso de investigación.

No obstante, como se ha advertido reiteradamente, el estudio se desarrolló desde una postura postpositivista o interpretativa. Esto, precisamente, ofreció la posibilidad de echar mano de la subjetividad o, si se quiere, de "esa intersubjetividad" propia de este tipo de paradigma, y mediante las entrevistas en profundidad llevadas a cabo con cada estudiante, valorar de forma intensiva los hallazgos a manera de una triangulación. Por lo cual, lejos de considerar un sesgo investigativo se ve como una oportunidad el hecho de que el docente haya sido el investigador que asignó las puntuaciones a los mapas conceptuales de los estudiantes, pues así reflexiona en su propia praxis y quehacer pedagógico para mejorar su enseñanza, su didáctica. Es una oportunidad también de revindicar al docente como investigador, puesto que a pesar de la reconocida importancia de su rol en la educación, gran parte de los estudios que se hacen en este campo son llevados a cabo sobre los docentes y no por ellos mismos. 
Se puede agregar, que aunque recientes estudios han asociado el uso los mapas conceptuales con relación a favorecer procesos metacognitivos y motivacionales del estudiantado, dentro de los límites de la investigación solo se enfocó la dimensión conceptual. Prospectivamente, sería interesante verificar la incidencia del uso de los mapas conceptuales sobre estas dimensiones y procesos en el grupo de aprendices.

Finalmente, se sugiere al profesorado el uso de mapas conceptuales para dinamizar los procesos de enseñanza y aprendizaje de las Ciencias Naturales. Para ello, será necesario que cada docente desarrolle un estudio concienciado sobre las teorías ausbeliana y Novak a fin de comprender la utilidad educativa de los mapas conceptuales.

\section{Referencias}

Aguilar, Manuel Francisco. (2006). El mapa conceptual: una herramienta para aprender y enseñar. Plasticidad y Restauración Neurológica 5(1), 7-17. Recuperado de https://www.medigraphic.com/cgi-bin/new/resumen.cgi?IDARTICULO=9331

Aguilera-Morales, David., y Perales-Palacios, Francisco. (2016). Metodología participativa en Ciencias Naturales. Implicación en el rendimiento académico y la actitud hacia la Ciencia del alumnado de Educación Primaria. ReiDoCrea, (5), 119-129. Recuperado de https://www.ugr.es/ reidocrea/5-13.pdf

Araujo, Nelcy., Bueno, Eliana., Almeida Flaveli., y Borsato, Dioniso. (2007). O petróleo e sua destilação: uma abordagem experimental no ensino médio utilizando mapas conceituais. Semina: Ciências Exatas e Tecnológicas, 28(1), 47-54. Recuperado de http://www.uel.br/revistas/uel/index.php/semexatas/article/view/1865

Arellano, José., y Santoyo, Margarita. (2009). Investigar con mapas mentales: procesos metodológicos. Madrid, España: NARCEA. Recuperado de https://bit.ly/35aKXfC

Athitaya, Nitchot., Wiphada, Wettayaprasit., y Lester, Gilbert. (2019). Personalized Learning System for Visualizing Knowledge Structures and Recommending Study Materials Links. E-Learning and Digital Media, 16 (1), 77-91. Rrecuperado de https://bit.ly/38qJtAb

Ausubel, David., Novak, Joseph., y Hanesian, Helen. (1983). Psicología Educativa. Un punto de vista cognoscitivo. México: Editorial Trillas.

Báez y Pérez de Tudela, Juan. (2014). El método cualitativo de investigación desde la perspectiva de marketing: el caso de las universidades públicas de Madrid (Tesis Doctoral). Universidad Complutense de Madrid, España. Recuperado de http://eprints.ucm.es/29615/1/T35974.pdf

Bergan-Roller, Heather,, Galt, Nicholas,, Helikar, Tomas,, y Dauer, Joseph. (2020). Using concept maps to characterise cellular respiration knowledge in undergraduate students. Journal of Biological Education, 54(1), 33-46. doi: https://doi.org/10.1080/00219266.2018.1541001 
Bramwell-Lalor, Sharon., y Rianfordb, Marcia. (2014). The effects of using concept mapping for improving advanced level Biology Students' Lower- and Higher cognitive skills. International Journal of Science Education, 36(5), 839-864. doi: https://doi.org/10.1080/09500693.2013.829255

Buitrago, Mauricio., y Chiappe, Andrés. (2019). Representation of Knowledge in Digital Educational Environments: A Systematic Review of Literature. Australasian Journal of Educational Technology, 35(4), 46-62. doi: https://doi.org/10.14742/ajet.4041

Byrn, Jenny., y Grace, Marcus. (2010). Using a concept mapping tool with a photograph association technique (CoMPAT) to edit children's ideas about microbial activity. International Journal of Science Education, 32(4), 479-500. doi: https://doi.org/10.1080/09500690802688071

Campanero, Juan., y Otero, José. (2000). Más allá de las ideas previas como dificultades de aprendizaje: Las pautas de pensamiento, las concepciones epistemológicas y las estrategias metacognitivas de los alumnos de ciencias. Enseñanza de las Ciencias: revista de investigación y experiencias didácticas, 18(2), 155-169. Recuperado de https://www.raco.cat/index.php/Ensenanza/article/view/21652

Campbell, Laurie. (2016). Concept Mapping: An "Instagram" of Students' thinking. The Social Studies, 107(2), 74-80. doi: https://doi.org/10.1080/00377996.2015.1124377

Cantinotti, Michael., Désormeaux-Moreau, Marjorie., y Balbinotti, Marcos. (2017). Mapping Psychology Students' Perspective on Group Peer-Tutoring in Statistics. Mentoring \& Tutoring: Partnership in Learning, 25 (4), 466-484. doi: https://doi.org/10.1080/13611267.2017.1403609

Cañas, Alberto., y Novak, Joseph. (2006). Re-examinando los fundamentos para el uso efectivo de mapas conceptuales.. Recuperado de http://cmap.ihmc.us/publications/researchpapers/Re-ExaminandoLosFundmentos.pdf

Ceylan, Özge., y Atabek, Elif. (2018). Analyzing the Effect of Concept Cartoon Usage on Students' Cognitive Structures Developments and Science Achievements through Flow Maps. Science Education International, 29(4), 238-249. Recuperado de https://files.eric.ed.gov/fulltext/EJ1205414.pdf

Coffey, Amanda., y Atkinson, Paul. (2003). Encontrar el sentido a los datos cualitativos. Estrategias complementarias de investigación. Medellín, Colombia: Editorial Universidad de Antioquia. Recuperado de https://bit.ly/3ki4u26

Cook, Leah. (2017). Using Concept Maps to Monitor Knowledge Structure Changes in a Science Classroom (Tesis doctoral). Universidad de Michigan, Estados Unidos. Recuperado de https://scholarworks.wmich.edu/dissertations/3139/

Creswell, John. (2012). Educational research: Planning, conducting, and evaluating quantitative and qualitative research ( $4^{\text {th }}$ ed.). United States: Pearson. 
Figueroa, Roberto., Utria, Carlos., y Colpas, Rafael. (2005). Entendimiento conceptual de estudiantes sobre conceptos en las ciencias experimentales. Tecné, Episteme y Didaxis, 18, 84-96. Recuperado de http://revistas.pedagogica.edu.co/index.php/TED/article/view/461/457

Figueroa, Roberto., Utria, Carlos., y Colpas, Rafael. (2006). Entendimiento conceptual de los estudiantes del nivel de básica secundaria sobre el concepto de ácido. Tecné, Episteme y Didáxis, (19), 22-31. Recuperado de http://revistas.pedagogica.edu.co/index.php/TED/article/view/1040/1052

Gardner, Grant., Lohr, Mary Ellen., Bartos, Stephen., y Reid, Joshua. (2019). Comparing Individual and Group-Negotiated Knowledge Structures in an Introductory Biology Course for Majors. Journal of 4 Biological Education, 53(3), 274-287. doi: https://doi.org/10.1080/00219266.2018.1469537

González-Jara, David., Cuetos, María., y Serna, Ana. (2015). Didáctica de las Ciencias Naturales en Educación Primaria. España: UNIR Editorial. Recuperado de https://reunir.unir.net/handle/123456789/4151

Glagiardi, Raúl. (1986). Los conceptos estructurales en el aprendizaje por investigación. Enseñanza de las Ciencias: revista de investigación y experiencias didácticas, 4(1), 3035. Recuperado de https://www.raco.cat/index.php/Ensenanza/article/view/50857

Gök Colak, Feride., y Tuğluk, Mehemet Nur. (2017). Investigation of the Cognitive Structures of Prospective Preschool Teachers on the Concepts of Circle, Disk and Annulus with the Word Association Test. Journal of Education and Practice, 8(29), 152-157. Recuperado de: https://www.iiste.org/Journals/index.php/JEP/article/view/39267

Gökçe, Kılıçoğlu. (2018). Determining Levels of 8th Grade Students of Secondary School to Understand Cognitive Structures and Concepts Concerning Concepts of Fundamental Citizenship. Journal of Education and Training Studies, 6(11), 156-167. doi: https://doi.org/10.11114/jets.v6i11.3505

Hacıoğlu, Yasemin., Yamak, Havva., y Kavak, Nusret. (2016). Pre-Service Science Teachers' Cognitive Structures Regarding Science, Technology, Engineering, Mathematics (STEM) and Science Education. Journal of Turkish Science Education, 13(special issue), 88-102. Recuperado de https://files.eric.ed.gov/fulltext/ED567757.pdf

Hermosillo, Saulo., y González, Pablo. (2012). Análisis de la organización Lógico-Conceptual en mapas conceptuales de estudiantes de Bachillerato sobre el tema de Reproducción. Proccedings of the Fifth International Conference on Concept Mapping (pp.5-8). Recuperado

de http://cmc.ihmc.us/cmc2012Proceedings/cmc2012\%20-\%20Vol\%203.pdf

Hernández, Roberto., Fernández, Carlos., y Baptista, Pilar. (2010). Metodología de la Investigación (5 $5^{\mathrm{a}}$ ed.). México: McGraw-Hill. 
Ibáñez, Alex., y Arribas, Silvia. (2012). La eficiencia de los mapas conceptuales como herramienta de gestión del feedback de evaluación en grandes grupos de aulas universitarias. Proccedings of the fifth International Conference of Concept Mapping. Recuperado de http://cmc.ihmc.us/cmc2012/cmc2012Program.html

Jaimes, Karla., y García, Diana E. (2013). El mapa conceptual y el uso de Cmaptools, conceptualización de sus aspectos didácticos. Sinéctica: Revista Electrónica de Educación, (41), 2-16. Recuperado de http://www.scielo.org.mx/scielo.php?script=sci arttext\&pid=S1665109X2013000200011 \&lng=es\&tlng=es

Karip, Fatih. (2019). Analyzing the cognitive structures of pre-service Teachers who take art education classes related to art concept. Universal Journal of Educational Research 7(1), 178-189. doi: https://doi.org/10.13189/ujer.2019.070123

Kemer, Gulsah. (2020). A comparisonof begining and expert supervisors' supervision cognitions. Counselor Education and Supervision, 59(1), 74-92. doi: https://doi.org/10.1002/ceas.12167.

Kinchin, Ian. (2010). Concept mapping in biology. The Journal Biological Education, 34(2), 6168. doi: https://doi.org/10.1080/00219266.2000.9655687

Kinchin, Ian. (2014). Concept mapping as a learning tool Higher Education: A critical analysis of recent reviews. The Journal of Continuing Higher Education, 62(1), 39-49. doi: https://doi.org/10.1080/07377363.2014.872011

López, Enrique., Shavelson, Richard, Nandagopal, Kiruthiga., Szu, Evan., y Penn, John. (2014). Etnically Diverse Students' Knowledge Structure in First-Semester Organic Chemistry. Journal of Research in science teaching, 51(6), 741-758. Recuperado de https://onlinelibrary.wiley.com/doi/full/10.1002/tea.21160

Mena, Luis. (2017). Muestra cualitativa. Una propuesta integradora. Investigación Qualitativa en Ciencias Sociales, (3), 180-190. Recuperado de https://webcache.googleusercontent.com/search?q=cache:rdA7TjWb8qwJ:https://proce edings.ciaiq.org/index.php/ciaiq2017/article/download/1155/1120/+\&cd=1\&hl=es\&ct=cln $\underline{\mathrm{k} \& \mathrm{gl}=\mathrm{CO}}$

Ministerio de Educación Nacional de Colombia [MEN]. (1994). Ley General de Educación (Ley 115 de 1994). Recuperado de https://www.oei.es/historico/oeivirt/rie04a06.htm

Moreira, Antonio. (2012). Mapas conceptuales y aprendizaje significativo. Revista Chilena de Educación en Ciencias, 4(2), 38-44. Recuperado de https://www.if.ufrgs.br/ moreira/mapasesp.pdf

Muñiz, Manuel. (2010). Estudios de caso en la investigación cualitativa. Recuperado de https://psico.edu.uy/sites/default/files/cursos/1 estudios-de-caso-en-la-investigacioncualitativa.pdf 
Nawani, Jigna., Von Kotzebue, Lena., Rixius, Julia., Graml, Michael., y Neuhaus, Birgit. (2018) Teachers' Use of Focus Questions in German Biology Classrooms: a Video-based Naturalistic Study. International Journal of Science and Mathematics Education, 16(8), 1431-1451. doi: https://doi.org/10.1080/09500693.2016.1213456

Novak, Joseph., y Gowin, D. Bob. (2002). Aprendiendo a Aprender. Recuperado de http://www.terras.edu.ar/biblioteca/3/3EEDU Novak-Gowin Unidad 1(1).pdf

Olivo, José. (2017). Caracterización de estudiantes exitosos: Una aproximación al aprendizaje de las Ciencias Naturales. CPU-e Revista de Investigación Educativa, (25), 114-143. Recuperado http://www.scielo.org.mx/scielo.php?script=sci arttext\&pid=S187053082017000200114 $\underline{\text { \&lng }=e s \& t \operatorname{lng}=e s}$

Pérez, Laura., y Gutiérrez, José. (2018). Los mapas conceptuales como instrumento de evaluación: Una experiencia de educación ambiental centrada en el estudio de ecosistemas acuáticos. Revista electrónica Actualidades Investigativas en Educación, 18(1), 1-35. doi: https://doi.org/10.15517/aie.v18i1.31840

Pineda, Claudia., y Afanador, Héctor. (2015). Diagnóstico de las concepciones sobre reproducción celular en estudiantes de grado séptimo, octavo y noveno de los colegios Miguel Antonio Caro IED y Justo Víctor Charry IED. Biografía Escritos sobre la Biología y su Enseñanza, 8(15). doi: http://dx.doi.org/10.17227/20271034.vol.8num.15biografia40.57

Rivadulla-López, Juan., García-Barros, Susana., y Martínez-Losada, Cristina. (2016). Los mapas conceptuales como instrumento para analizar las ideas de los estudiantes de Maestro de Educación Primaria sobre qué enseñar de nutrición humana en Educación Primaria. Revista Complutense de Educación, 27(3), 1247-1269. doi: http://dx.doi.org/10.5209/rev RCED.2016.v27.n3.47704

Roig, José., y Araya, Jessica. (2013). El uso del mapa mental como herramienta didáctica en los procesos de investigación realizados por los estudiantes de licenciatura de la carrera de Ingeniería Industrial. e-Ciencias de la Información,3(2), 1-22. doi: https://doi.org/10.15517/eci.v3i2.10658

Rojas, Belkis. (2014). Investigación cualitativa. Fundamentos y praxis. Caracas, Venezuela: Fondo Editorial de la Universidad Pedagógica Experimental Libertador (FEDUPEL). Recuperado de https://gsosa61.files.wordpress.com/2015/11/investigacion-cualitativarojas-2014-comprim-1.pdf

Sánchez-Castaño, Jairo., Castaño-Mejía, Olga., y Tamayo-Alzate, Óscar. (2015). La argumentación metacognitiva en el aula de ciencias. Revista Latinoamericana de Ciencias Sociales, Niñez y Juventud, 13(2), 1153-1168. Recuperado de https://www.redalyc.org/pdf/773/77340728042.pdf 
Sellmann, Daniella., Liefländer, Anne., y Bogner, Franz. (2015). Concept maps in the classroom: A new approach to reveal students conceptual change. The Journal of Educational Research, 108(3), 250-257. doi: https://doi.org/10.1080/00220671.2014.896315

Subramaniam, Karthigeyan., y Esprívalo, Pamela. (2015). An analysis of prospective teachers' knowledge for constructing concept maps. Journal Educational Research, 57(3), 217-236. Recuperado de https://doi.org/10.1080/00131881.2015.1050845

Tokcan, Halil. (2017). Determining the Turkish World Perceptions of Candidate Social Studies Teachers through Word Association Test. Universal Journal of Educational Research, 5(8), 1386-1395. doi: https://doi.org/10.13189/ujer.2017.050812

Tripto, Jaklin., Zvi Assaraf, Orit., y Amit, Miriam. (2018). Recurring patterns in the development of high school biology students' system thinking over time. Instructional Science, 46, 639680. doi: https://doi.org/10.1007/s11251-018-9447-3

Utria, Carlos. (2000). Entendimiento conceptual logrado por estudiantes en un curso de químico general de corte constructivista (Tesis de grado). Universidad de Puerto Rico.

Wei, Wei. y Yue, Kwok-Bun. (2016). Using Concept Maps to Teach and Assess Critical Thinking in IS Education Paper. Presented at the 22nd Americas Conference on Information Systems. San Diego, United States of America.

Wei, Wei. y Yue, Kwok-Bun. (2017). Integrating Concept Mapping into Information Systems Education for Meaningful Learning and Assessment. Information Systems Education Journal (ISEDJ), 15(6), 4-16. Recuperado de https://files.eric.ed.gov/fulltext/EJ1151907.pdf

Zvacek, Susan,, Restivo, Maria, y Chouzal, María. (2013). Concept Mapping for Higher order thinking. International Journal of Enginering Pedagogy, 3, 6-10. doi: http://dx.doi.org/10.3991/ijep.v3iS1.2401 
Revista indizada en

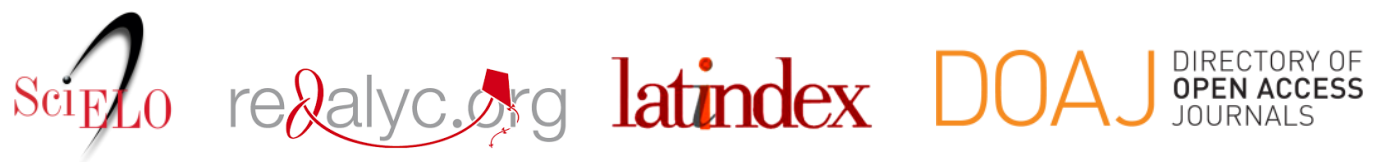

Distribuida en las bases de datos:

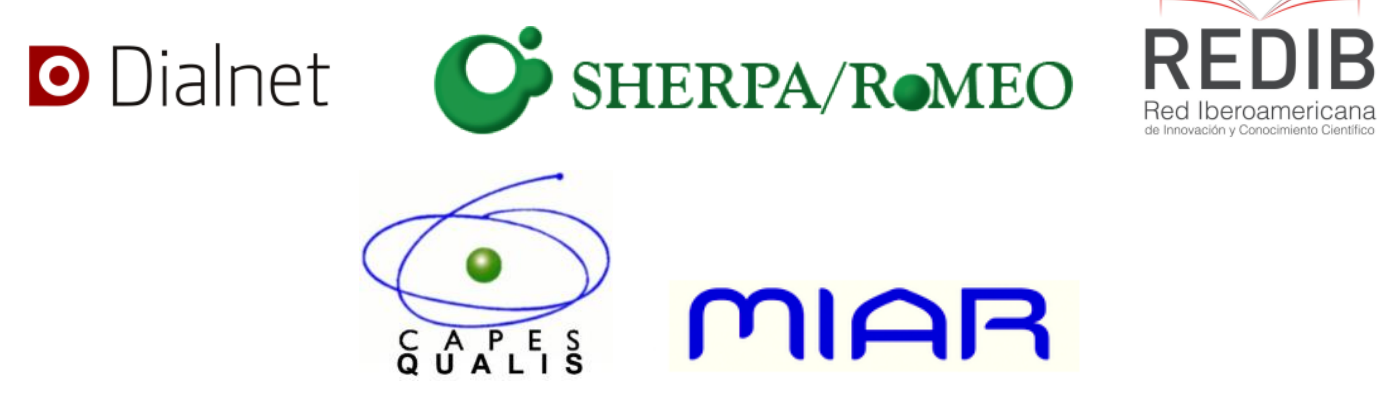

